\title{
LA VARIACIÓN LINGÚISTICA Y EL ESPAÑOL DE AMÉRICA
}

\author{
Bernard Pottier \\ Universidad de París IV
}

Los lingüistas siempre se han interesado por lo más específico de una lengua, en particular los dialectólogos, y por eso disponemos ahora de algunos excelentes Atlas para varias regiones de España y algunas de Hispanoamérica.

Sin embargo, las síntesis son escasas, y vamos a ver por qué.

Hay un hecho general, objetivo: el concepto de variación es un universal del funcionamiento de las lenguas.

Son muy conocidas las grandes distinciones de la diacronía (el tiempo), la diatopía (el espacio), los niveles diastrático (los estratos sociales) y diafásico (el registro), tal como las utiliza Eugenio Coseriu. Otros añaden la dimensión diamésica, o sea lo relativo a la elección de medios expresivos, como el canal de la lengua escrita o de la lengua hablada, u otros medios semiológicos.

A cada uno de estos parámetros universales corresponde una terminología en -lecto que, respectivamente, da el cronolecto, el regiolecto, el sociolecto, el tecnolecto y el mesolecto.

En realidad, cada uno de nosotros, cuando habla o escribe, está realizando una variedad idiolectal, es decir, una combinación momentánea de variables de los cinco lectos antes mencionados.

En esta serie de términos en -lecto hay uno cuyo uso es muy delicado, el de dialecto. En su acepción científica, el dialecto es una lengua o una variedad de una lengua circunscrita a un ámbito geográfico determinado, sin que aparezca connotación alguna.

Al referirse a varios rasgos característicos de una población de los Andes 
venezolanos, donde se oye truje y vide, vos cantás y tomé fue leche, dice Angel Rosenblat:

Como el habla de esa comunidad es afin a la de otras comunidades, vecinas y lejanas, que constituyen en conjunto el mundo de habla española, nos hemos acostumbrado a considerar sus modos expresivos como dialectales y a darles la denominación, mitad comparativa, mitad peyorativa, de rústicos. Es evidente que se aplica así un patrón externo, un punto de vista extraño a la comunidad misma, en nombre de una abstracción que se llama lengua española. Pero el habla de esa comunidad es irreprochable tal como es, y cualquiera que se acerque a ella, como visitante o como estudioso, debe hacerlo con el mayor respeto. Dentro de ella cabe una rica gama de matices estilisticos, desde la ramplonería más vulgar hasta la elocuencia y la gracia.

Queda claro que sólo se puede hablar de diferencias y divergencias en la medida en que se reconocen ciertas semejanzas y afinidades.

En cuanto a esa "lengua española", dice muy bien Manuel Alvar que

es el suprasistema abarcador de todas las realizaciones de la lengua, la lengua abstracta que todos aceptamos, que tiene virtualidad en la lengua literaria escrita, y que ninguno habla.

Ahí está la especificidad de una lengua de gran difusión.

El español, como el inglés o el francés, se puede definir como un conjunto de virtualidades, de potencialidades que nunca se realizan en su totalidad, sino que se manifiestan a través de los parámetros ya señalados.

Dicho de otro modo, enumerar las diferencias implica referirse a una mínima base unitaria virtual.

Si pasamos a las prácticas, vamos a ver que la documentación tiene que ser interpretada constantemente.

Tomemos uno de los mapas del tan rico atlas etnolingüístico de Andalucía de M. Alvar. Para un objeto tan concreto como el "cabezal delantero" del carro, aparecen formas tan variadas como cabezala, telere, lantere, trasera, tabla zaga, trascón o pértigo.

Vamos a Colombia y la "carnicería" se dice también el mercado, la pesa o la fama (del nombre de una tienda particular).

$\mathrm{La}$ riqueza onomasiológica aparece claramente en este tipo de encuesta y el concepto de exhaustividad no se puede aplicar.

Ahora, aun cuando se limita la investigación a un solo punto, tampoco hay unidad en las respuestas. En el caso de una gran ciudad interfieren otros 
parámetros. Aqui van dos o tres ejemplos sacados de la encuesta sobre el habla culta.

Para designar la "máquina para cortar el césped", contestaron en Madrid lo siguiente:
la segadora, 6 veces
la podadera, $1 \mathrm{v}$.
el corta-césped, $5 \mathrm{v}$.
el cepillo, $1 \mathrm{v}$.

la cortadora de césped, $1 \mathrm{v}$.

En México fue:
la podadora, $17 \mathrm{v}$.
la máquina de cortar pasto, $2 \mathrm{v}$.
la segadora, $4 \mathrm{v}$.
la trilladora, $1 \mathrm{v}$.
la cortadora de pasto, $3 \mathrm{v}$.

Para el comportamiento social "ligar", salieron en Madrid:

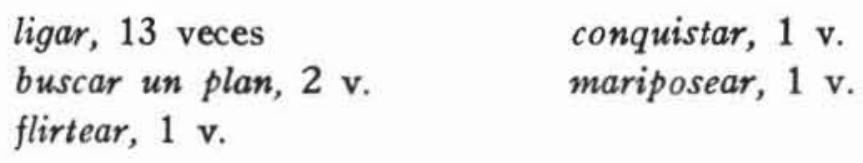

y en México:
ligar, $18 \mathrm{v}$.
flirtear, $1 \mathrm{v}$.
pescar, $1 \mathrm{v}$. enamorar, $1 \mathrm{v}$.
buscar planes, $1 \mathrm{v}$.
mariposear, $1 \mathrm{v}$.
conquistar, $1 \mathrm{v}$.

Este tipo de comparación se puede ampliar con los resultados obtenidos en Caracas, Bogotá o Santiago de Chile.

La interpretación sería que, a pesar de diferencias locales, hay bastantes zonas de intersección y que además estas formas dependen de cómo se hicieron las preguntas. En realidad, las palabras deberían ponerse en su contexto, en su entorno sintáctico-semántico. Se conservaría de este modo la secuencia discursiva o la fraseología en que venía efectivamente la palabra.

Un paso más y se llega a la variedad textual, pocas veces tomada en cuenta, sobre todo en un espacio tan vasto como el de la lengua española.

Piénsese en lo que sería una comparación entre, pongamos:

- el discurso de un locutor deportivo ante un encuentro futbolístico;

- el texto de una carta comercial con sus tan pesados giros;

- un diálogo entre dos campesinos mexicanos; 
- una declaración de un representante de una comunidad peruana andina ;

- un cuento de Borges o un romance de Garcia Lorca.

Todos estos discursos se realizan a partir de un fondo común, de un núcleo de competencia lingüística que compartimos todos, que hace que los entendamos, más o menos, a pesar de las notables divergencias en todos los niveles de distinción antes aludidos.

Como es natural, los especialistas han tratado de establecer zonas dialectales dentro de las grandes áreas lingüísticas. Vamos a presentar rápidamente dos casos concretos: el de la regionalización idiomática en Francia, y el de la zonificación dialectal de Hispanoamérica.

Desde hace más de un siglo, los dialectólogos han dividido a Francia en dos zonas, la de lengua de "oïl" y la de lengua de "oc". Pero en seguida surgieron dos zonas mixtas: la del croissant o media luna, faja de contacto entre las dos áreas, y el franco-provenzal cuyo mismo nombre indica claramente el carácter complejo. Pero esto es poca cosa.

En el año 1988 sale un decreto en el que se prevé la posibilidad de presentar para el bachillerato como materia obligatoria u opcional, "lenguas regionales" de Francia.

Hubo que establecer un inventario de dichas lenguas y tener en cuenta las variantes que se reconocían en cada caso:

- el vascuence, con sus tres dialectos del lado francés

- el bretón, con cuatro dialectos

- el catalán rosellonés

- el corso, como dice el texto: "en su variedad local y en su diversidad dialectal"

- las lenguas regionales de Alsacia.

Ahora, cuando el texto se refiere a la zona occitana, ya es harina de otro costal. Primero se enumeran, en orden alfabético, para no disgustar a nadie, las siete grandes variedades:

"auvergnat, gascon, languedocien, limousin, nissart, provençal, vivaroalpin".

Luego, para cada una de ellas, se mencionan varias subdivisiones. Para 
el auvergnat, distintos sistemas gráficos; para el gascón, dos variedades; para el provenzal, "rhodanien, maritime, alpin", etc., etc....

Una verdadera locura.

Y dirán ustedes, ¿qué pasa con el francés de oill?

Pues por razones psicopolíticas relativas a la provincia de Bretaña, se ha creado una posible prueba oral de "gallo", el habla de oil del este de Bretaña que según el decreto también tendría sus variantes.

No sé si los más sabios de entre los lectores imaginarian que Francia tuviera más de 20 variantes idiomáticas reconocidas a nivel de bachillerato. $\mathrm{Y}$ luego se habla del centralismo francés ...

Lo malo es que con esta igualación generalizada de valores, se asimilan en el tratamiento verdaderas lenguas con cultura e historia, y hablas a veces de difícil identificación que sólo conservan algunos vestigios de tiempos pasados.

Veamos ahora el caso de Hispanoamérica, recordando algunas de las etapas de la investigación.

$\mathrm{Me}$ parece que son cuatro los criterios utilizados.

El primero fue la consideración de la existencia de las lenguas indígenas en el momento de la Conquista, lo que llevó en 1921 a Pedro Henríquez Ureña a proponer cinco zonas, como bien se sabe, en relación con el nahuatl, el caribe y arahuaco, el quechua, el mapuche y el guaraní. Ya antes, en 1882, el cubano Juan Ignacio de Armas y Céspedes había sugerido cuatro zonas similares en sus Orígenes del lenguaje criollo. Sobre el papel de las lenguas indigenas hicieron comentarios Bertil Malmberg y Ángel Rosenblat, pero es evidente que de ninguna manera estas lenguas (y otras no citadas) pueden ser el factor determinante de la diversificación dialectal americana.

Sabemos por experiencia que se notan en seguida las diferencias fónicas en el interlocutor, y por otra parte el investigador puede con bastante facilidad identificar los rasgos fonéticos y sus impactos fonológicos.

Ya en 1958, José Pedro Rona trató de jerarquizar los rasgos fónicos y morfológicos

Desde el punto de vista teórico, cualquier fenómeno lingüístico interesa a la investigación dialectal. Cualquier hecho observado, publicado y estudiado acrecienta nuestro caudal de conocimientos acerca de los hablares hispanoamericanos. En un plano rigurosamente metodológico, sin embargo, y si se toma en cuenta todo lo dicho anteriormente, algunos hechos son más importantes que otros para el adelanto de las investigaciones sucesivas. Es evidente, por ejemplo, que el fenómeno del voseo, que implica todo un nuevo paradigma verbal, tiene una importancia mucho mayor que la aparición de una $-e$ de 
apoyo al final de las palabras que terminan en $-l$ o $-r$. La importancia radica aqui en la incidencia del fenómeno en el cuadro total de la realidad lingüística, y en el impacto de este fenómeno en la conciencia del hablante y del oyente, en cuanto pone de manifiesto con mayor intensidad el hecho de la fragmentación dialectal. La entonación, por ejemplo, es sentida vivamente por el oyente procedente de otras zonas del Continente, mientras que el ensordecimiento de la mediopalatal fricativa sonora pasa casi desapercibido, a pesar de su frecuencia. En este sentido, podemos considerar como "importantes" aquellos fenómenos que, una vez producidos, siguen actuando, a su vez, en la conciencia de los hablantes.

\section{Sigue Rona insistiendo en}

la necesidad de dar total preferencia a los fenómenos fonéticos y fonológicos, como base primera para el estudio de cualquier otro campo dialectal.

Esta reflexión le sirvió de base para la propuesta de clasificación que presentó en el Congreso del 63 sobre Presente y futuro de la lengua española.

Seleccionó cuatro rasgos (el yeísmo, el žeísmo, el voseo y la morfología verbal correspondiente), lo que le proporcionó 16 áreas combinatorias, a las que añadió siete subclases.

Estas 23 zonas son de extensión muy variada, y sobre todo no toman en cuenta los resultados de las encuestas en cada uno de los países cuando se han considerado otros fenómenos posiblemente más pertinentes (por ejemplo en el Río de la Plata, en México o en Colombia).

Le siguió en 1962 D. Lincoln Canfield, quien utilizó ocho rasgos fonéticos para llegar a una conclusión bastante negativa. He aquí lo que dice de la noción de "zonas lingüísticas" :

Se observa, pues, que no se pueden establecer zonas americanas de pronunciación que correspondan a las entidades políticas actuales, ni tampoco a zonas de influencia léxica indigena.

Las zonas americanas de pronunciación en general corresponden a la accesibilidad de los territorios para la evolución fonológica del castellano andaluz durante los siglos xVI y xvir. Por casualidad topográfica, las regiones altas representan generalmente los principios del andalucismo y, las costas, el pleno desarrollo.

Cuando vuelve a desarrollar su estudio en 1988, presenta con más fuerza aún su escepticismo:

Zonas de América que distaban entre sí miles de kilómetros se colonizaron simultáneamente y recibieron idéntico estadio de lengua y cultura hispánicas a través de los mismos puertos del sur de Espafía. Por esta razón, no se encuentran en América netas isoglosas correspondientes a rasgos estructurales, 
y el intento de delimitar áreas lingüisticas en dicho Continente produciria un dibujo semejante a la piel de leopardo.

Es probable que esta "piel de leopardo" aluda al estudio que publicó primero en 1969 Melvyn Resnick explicando que el número de áreas dependía matemáticamente de la cantidad de rasgos considerados:

$$
\begin{array}{llll}
\text { - con } 2 & \text { se llega a } & 4 \text { zonas } \\
-" & 4 & \prime & 16 \quad " \\
-" & 8 & \prime & 256 \text { (o sea } 2^{8} \text { ). }
\end{array}
$$

Es decir, que cuanto más sabio o serio el investigador, menos posibilidades tendrá de presentar una división utilizable del continente americano.

Cito el comentario que hace Canfield en 1988 del trabajo de Resnick de 1975 y vale la pena meditarlo:

\begin{abstract}
Llevado por estas consideraciones y por el hecho de que algunos autores tienden a intentar una delimitación clara en zonas, Melvyn Resnick (1975) decidió dejar de lado consideraciones taxonómicas y estudiar los datos disponibles sobre las variantes fonológicas en la totalidad del área. Asi, utilizando técnicas de discriminación mediante rasgos distintivos, procedió a dividir la totalidad del corpus en unidades de información especificables en forma binaria que, por la presencia o la ausencia de un rasgo, crean un dialecto. En teoría, cada distinción produce automáticamente dos “dialectos" que están relacionados con países, regiones, ciudades, niveles sociales, edad o modos de expresión. Aunque la principal aportación de su estudio sea metodológica, a modo de ilustración Resnick ha reunido muchas de las variaciones fonológicas del español de América y, al mismo tiempo, ha demostrado la existencia de similaridades entre lugares muy separados, así como la existencia de parámetros tanto verticales como horizontales en dialectología hispánica.
\end{abstract}

El último intento moderno, basado en rasgos fónicos, quizá sea el de Juan Zamora Munné y Jorge Guitart (Bogotá, 1982). Dicen que toman "los tres rasgos" que consideran "más válidos y útiles para una clasificación primaria del español americano, los relacionados con /x/, /s/ y voseo".

Esto les lleva a constituir nueve zonas, acompañada cada una de varios comentarios sobre distinciones internas, $\sin$ que se note nada realmente nuevo.

Los intentos basados sobre el léxico son escasos. Cualquier lector de la Semántica hispanoamericana (1962) de Ch. Kany se dará cuenta de la inestabilidad de la repartición léxica a través del área de habla hispana. Mencionaré el estudio que publicó en $L E A$ Philippe Cahuzac sobre las denominaciones del campesino, de tipos de habitaciones y de fenómenos atmosféricos. 
Su conclusión, muy parcial naturalmente, es que se pueden distinguir cuatro zonas que coinciden relativamente con las de Henríquez Ureña.

El cuarto y último criterio sería el gramatical, y otra vez podemos citar a Ch. Kany con su utilísima Sintaxis hispanoamericana (1969) y a J. M. Lope Blanch que dirigió la elaboración del muy rico Cuestionario morfosintáctico (1972) sobre el habla culta.

Ya hace años decía Lope Blanch lo siguiente:

Por supuesto que sería de desear que se prestara mayor atención de la que se les ha concedido hasta ahora a los fenómenos gramaticales. En muchos de los trabajos publicados últimamente se atiende sólo a los hechos fonéticos y léxicos del idioma, en tanto que la estructura gramatical, columna vertebral de la lengua, queda en el olvido. Durante siglos, la gramática se ha hecho exclusivamente sobre la lengua escrita. La cambiante realidad de la lengua hablada parecía imposible de asir. Cierto que la compilación y el estudio de los fenómenos gramaticales -especialmente del habla- requiere más esfuerzo, dada la complejidad superior de ciertas construcciones; pero hoy disponemos de medios adecuados para fijar materialmente la lengua hablada y para reproducirla en toda su complicada realidad. Una sola peculiaridad sintáctica puede resultar más significativa que toda una serie de particularidades léxicas.

Hasta ahora nadie ha podido responder al desafío.

Establecer normas es generalmente hacer una reforma y el campo de más fácil aplicación es sin duda el de la ortografía. Todas las grandes lenguas tienen que modificar de vez en cuando sus grafías. Se conocen las divergencias entre el inglés americano y el británico. Las grafías portuguesa y brasileña se oponen en varias manifestaciones menores pero surgen polémicas cuando se trata de unificarlas, porque en realidad Portugal y Brasil quieren conservar su especificidad.

Se sabe que en Francia hay una tradición ortográfica muy fuerte. Hace poco se reunió una Comisión, se publicó un decreto, y parece que nadie lo va a aplicar por diversos motivos que no cabe explicar aquí. Señalaré como anécdota que en la lista de modificaciones gráficas aparecen algunas palabras españolas que tendrán que llevar escrito el acento agudo como péséta, sombréro o zarzuéla, lo que naturalmente es sólo para la vista. En cuanto a la famosa paella, que generalmente sale con buena ortografía en el menú de los restaurantes franceses, tendremos que escribir la feísima secuencia paélia.

Volvamos a Espafía que tiene relativamente menos problemas. Se abandonaron las propuestas del siglo pasado, pero se encuentran a veces grafías 
anormales, como es el caso de Francisco Santamaría, quien en 1959 escribe hoi o sujerir.

Las reformas propuestas estos últimos años por la Academia Española parecen muy sensatas. El papel regulador de la Academia es notable. En Francia, la norma la constituyen las publicaciones de empresas privadas (como Larousse o Le Robert). Fue para mí una sorpresa ver el éxito que tuvo y tiene el "Libro de estilo" publicado por El País, el cual refleja las dificultades que entraña una situación de multilingüismo y las evoluciones del español.

Se declara que El País "se escribe en castellano" y que los nombres de lugares serán los de las Autonomías excepto los de regiones o capitales de provincia. Así que se escribirá Cataluña con ñ, y Orense con $o$ - inicial. Se establece de este modo un criterio jerárquico de difusión o extensión: nacional / $\mathrm{v} /$ regional.

El "Libro de estilo" fija grafías (los primeros kmer se volvieron jemer), pronunciaciones (Rumania y no Rumania, que se oye muchísimo), morfología (duodécimo y no décimosegundo) y naturalmente el léxico (extranjerismos, neologismos, etc. ...).

Los autores también tuvieron que enfrentarse con distintos problemas gramaticales y daré nada más un ejemplo. Se recomienda la concordancia entre el sujeto y el verbo en "el $60 \%$ de los encuestados opina que ..." y no "opinan". Pero habrá excepción en el caso de "el $5 \%$ de las mujeres está embarazado", que no suena bien no por el número del verbo sino por el masculino formal del adjetivo. Está bien. Pero si por una parte "un $60 \%$ " en sí no puede opinar, y si por otra hay que decir "un millón de personas ocupan la calle", sería más coherente recomendar la concordancia ad sensum en todos los casos.

Para el lingüista que describe una variedad de lengua, cualquier subsistema que funcione bien y corresponda a un medio de comunicación dentro de una comunidad determinada es válido. Se trata en este caso de una valoración independiente de cualquier juicio o comparación.

Angel Rosenblat ha comentado perfectamente este punto de vista. Dice:

La lengua es, para el lingüista, un sistema de signos expresivos, objeto de estudio científico. Para la sociedad, es un instrumento de comunicación. Como tal, su imperativo categórico es la claridad, lo cual implica una serie de condiciones (la primera, evitar toda anfibología o incongruencia). Si su carácter instrumental fuera la condición esencial o única, el criterio de corrección sería relativamente fácil, y responderfa a imperativos de máxima economía. Haiga es tan claro como haya, méndigo tanto como mendigo. "Me se ha olvidado" es $\tan$ claro como "Se me ha olvidado". "Aquí habemos muchos hombres dispuestos a sacrificarnos" es más claro que "aquí hay ...". "Eso se los digo a ustedes con mucho gusto" parece más claro que "se lo digo...", 
al menos en Hispanoamérica. "Han habido muchos accidentes" es tan claro o más claro que "ha habido...". Hay, pues, algo en la lengua que no es sólo su valor instrumental y que hace que el haiga, el méndigo, el me se, el habemos, el se los, el han habido se consideren inadmisibles.

Se consideran inadmisibles - claro está-, no por los que usan esas formas, sino por otros hablantes, en nombre de una norma externa, que es la de la gente culta.

Este tipo de observación fue la base de los estudios que se realizaron en España y por toda América con el fin de establecer claramente la calidad de las variantes del español y su extensión.

He aquí cómo Juan Miguel Lope Blanch presentaba el proyecto hace unos treinta años:

A la dialectología hispanoamericana le aguardan tareas inmensas y de urgente realización, que exigirán el esfuerzo mancomunado de muchos investigadores.

Quizá habria que empezar por conocer detalladamente el estado verdadero actual del español hablado en los grandes núcleos urbanos de América; es decir, de los grandes centros de irradiación lingüistica, en donde se gestan las modalidades fundamentales del habla de cada pais y desde donde se extienden las normas idiomáticas sobre las hablas regionales, sofocándolas o encauzándolas hacia una nivelación nacional. Buenos Aires, Bogotá, Santiago, México, La Habana, Montevideo, Caracas, Lima y otras capitales son otros tantos fo$\cos$ de efervescencia lingüistica, cuyas tendencias evolutivas pueden no coincidir entre sí, ni con el ideal general de lengua. Ellas suelen dar la norma expresiva al resto del país y ellas representan las principales modalidades del español americano.

De ahí nació el excelente Cuestionario para el estudio coordinado de la norma lingüística culta.

En la solapa de esta publicación del año 1972 se lee que

La publicación tiene un señalado valor simbólico, por cuanto estos cuadernos van a servir para organizar la koiné de nuestra lengua en ambos lados del Atlántico.

No creo que koiné sea la palabra adecuada, porque de ninguna manera se tiende a crear una superlengua común, sino a conocer primero el conjunto de las variedades regionales a nivel del habla culta, tomada como referencia.

Esta primera etapa se ha concretado con tres tipos de publicaciones de gran importancia para los investigadores de la lengua española :

- la transcripción de las cintas de las encuestas

- las respuestas al cuestionario temático 
- y las monografías sobre problemas gramaticales cuyos autores hasta ahora no habian podido aprovecharse de un material tan rico.

Con esta documentación hay trabajo todavía para muchos años.

He sabido de otras iniciativas de constitución de corpus con la ayuda de los medios modernos de la informática, de modo que se va a enriquecer aún más el caudal de datos disponibles para la investigación.

Las primeras conclusiones sobre las variedades del español llevan a considerar que es imposible hablar de una norma.

Esta idea ya la había formulado claramente el Congreso del 63:

La Comisión considera que toda acción rectora del futuro de la lengua española tendiente a la deseable unificación de la lengua cultivada debe hacerse con absoluto respeto a las variedades nacionales tal como las usan los hablantes cultos, y teniendo en cuenta que la unidad idiomática no es incompatible con la pluralidad de normas básicas, fonéticas y de otro tipo que caracterizan el habla ejemplar y prestigiosa de cada ámbito hispánico.

y también más adelante se decía :

Por lo que se refiere a la defensa y mantenimiento de la unidad idiomática, se ha comprobado en general, en el seno de la Comisión, una actitud comprensiva, flexible y positiva de tolerancia, y más aún de franca aceptación de la pluralidad de normas de ejemplaridad existentes en el nivel del habla culta de los varios países hispánicos, pluralidad que no afecta realmente a la unidad esencial de la lengua como instrumento de comunicación panhispánica.

Queda, para el lingüista, una pregunta: ¿ cómo se realizó la diferenciación lingüistica americana?

Se conocen bastante bien los procesos de dialectalización de la Península.

Cuando se pasa a América, se multiplican los factores que entrarían en la evolución de las variedades españolas allí exportadas. ¿Quién habla qué, con quién, en qué condiciones? Es un problema de lingüística general ya estudiado para otras áreas del mundo.

Lope Blanch hizo algunas hipótesis a este propósito :

Sería conveniente aclarar hasta qué punto la simplificación de, al menos, algunos aspectos del sistema lingüístico castellano obedece a la condición de lengua periférica o de lengua de colonización que tiene el espaffol de América. Simplificación o reducción morfológica que se compensa, por otra parte, mediante el crecimiento de las formas analíticas, perifrásticas. Los reajustes del sistema morfosintáctico podrían confrontarse con los reajustes realizados en 
las diferentes regiones dentro del sistema léxico, es decir, con los cambios semánticos nacionales. Tal vez en esa condición de lengua periférica se halle la explicación del carácter arcaizante de algunas hablas hispanoamericanas, así como del impetu con que se han desarrollado en ellas algunas de las tendencias evolutivas inherentes al sistema castellano.

Todas estas consideraciones me sugieren la conclusión siguiente.

Con toda sinceridad, cuando se trata de una lengua tan extensa, difundida y hablada como el español, ninguna frontera algo densa de rasgos lingüísticos se puede establecer.

La lección del ensayo de Resnick es justamente que cuantos más criterios se eligen, más miniáreas vamos a crear.

Parece que lo que predomina en los hablantes es un sentimiento de afinidad areal que hace que se hable de un español caribeño o andino o rioplatense o andaluz, refiriéndose así a un conjunto impresivo que naturalmente procede de factores fónicos (articulaciones, entonaciones) y también de giros y del vocabulario.

Los tests de reconocimiento e identificación son menos discutibles que la zonificación a la que llegan los científicos, debemos reconocerlo.

Como todas las grandes lenguas, el español es un abanico de variantes dentro de una unidad comunicacional.

Los lingüistas pueden discutir sobre la existencia o la pertinencia de tal o cual fenómeno particular.

Los hablantes que se declaran hispanófonos saben que practican un mismo idioma, esa abstracción tan presente que se llama la lengua española.

\section{BIBLIOGRAFFA}

Alvar, Manuel: "Lengua y dialecto: delimitaciones históricas estructurales", Arbor, LXXVI, 1970, n. ${ }^{\circ} 299$.

Armas y Céspedes, J. I.: Origenes del lenguaje criollo, La Habana, 1882.

Cahuzac, Philippe: "La división del español de América en zonas dialectales. Solución etnolingüística o semántico-dialectal", LEA, II, 1980, 385-461.

Canfield, D. L.: La pronunciación del español en América, Bogotá, 1962 (2. ${ }^{a}$ ed., 1988).

Coseriu, Eugenio: “Los conceptos de 'dialecto', 'nivel' y 'estilo de lengua', y el sentido propio de la dialectología", $L E A$, III, 1981, págs. 1-32.

El Simposio de Cartagena (1963), Bogotá, 1965.

Encwesta léxica del habla culta de Madrid, Madrid, 1981.

Henrfquez UreñA, Pedro: "Observaciones sobre el espafiol de América", RFE, 1921, págs. 357-390.

KanY, Ch. E.: Semántica hispanoamericana, Madrid, 1962.

- Sintaxis hispanoamericana, Madrid, 1969.

Léxico del habla culta de México, México, 1978. 
Lope Blanch, J. M.: Cuestionario para el estudio coordinado de la norma lingüistica culta, t. II, México, 1972.

El español de América, Madrid, 1968.

ResNick, M. C.: "Dialect zones and automatic dialect identification in Latin American Spanish", Directory of the Amcrican Association of Teachers of Spanish and Portuguesc, 1969, págs. 553-567.

- Phonological Variants and Dialect Identification in Latin American Spanish, La Haya, 1975.

Rona, J. P.: Aspectos metodológicos de la dialectología hispanoamericana, Montevideo, 1958.

"El problema de la división del español americano en zonas dialectales", Prcsente y futuro de la lengua española, Madrid, I, 1964, págs. 215-226.

Rosenblat, Angel: "El criterio de corrección lingüistica. Unidad o pluralidad de normas en el español de España y América", El simposio de Bloomington, Bogotá, 1967, págs. 113-153.

Zamora Munne, J. C., y Guitart, J. M.: Dialectología hispanoamericana, Salamanca, 1982. 